\title{
MEMORIA, HISTORIA Y PATRIMONIO CULTURAL
}

MEMORY, HISTORY AND CULTURAL HERITAGE

Enviado em 04 de setembro de 2015

Aceito em 20 de novembro de 2015

Jesús Antonio Machuca Ramirez ${ }^{1}$

Resumen: En el mundo contemporáneo, se constata una pérdida de memoria y de patrimonio cultural, a lo que ha seguido un fenómeno de saturación de información que se presenta como si fuese su restauración. Por su naturaleza, la memoria no es algo que se pueda simplemente perder o reponer y sólo se concibe como concepto en relación con el olvido. La memoria se revela a su vez como algo problemático. Es justo señalar, que también mediante la memoria se invierte el sentido de los hechos históricos; es un depósito de ilusiones de restauración muy distantes en el tiempo y un fardo que llevan los sobrevivientes de las desgracias colectivas. Aún así, es lo que hace posible que haya un patrimonio cultural y una recuperación del sentido.

Palabras-clave: Memoria. Memoria colectiva. Memoria étnica. Patrimonio cultural.

Abstract: The modern world has experienced a loss in memory and cultural heritage which has been followed by a barrage of information that we are led to believe is a restoration of that which was lost. By nature, memory is not something that can be simply lost and replaced, and memory can only be conceived of in juxtaposition with oblivion. At the same time, memory reveals itself as problematic. It is appropriate to state that memory can invert the meaning of historical events; it harbors illusions of by-gone days, and is a burden that survivors of collective tragedies always carry with themselves. Even so, memory is what makes cultural heritage and discovery of meaning possible.

Keywords: Memory, Collective Memory, Ethnic Memory, Cultural Heritage.

\footnotetext{
${ }^{1}$ Antropólogo, Professor Investigador Titular do Instituto Nacional de Antropología e Historia. Especializado em antropologia jurídica, Patrimônio cultural e diversidade cultural. E-mail: machucaantonio@hotmail.com
} 
La reflexión contemporánea sobre la memoria nos conduce a una interrogante insoslayable sobre lo que se podría considerar como un síntoma de nuestro tiempo. Este se hace patente con la crisis sobre la concepción de la Historia en el cambio de siglo. El surgimiento del interés por la memoria y la proliferación de los estudios en torno de la misma, ha sido una muestra de ello. Todo parece indicar que hay algo, que -de forma inédita- ha cambiado en nuestra relación con el pasado y el sentido de la Historia, lo que se refleja agudamente en la conciencia historiográfica y antropológica actual.

En los años recientes, se asiste a un fenómeno acentuado de patrimonialización que denota un contraste con respecto a dos tendencias relacionadas con la memoria: un fenómeno de proliferación y registro desmesurados de la información y remmemoración, así como de angustia ante la velocidad de los cambios que suscitan las nuevas tecnologías en la sociedad moderna y producen una sustitución acelerada y creciente de los bienes de todo tipo.

A ello se aúna la destrucción deliberada en muchos casos, de bienes culturales que habían perdurado hasta el presente a lo largo de siglos y milenios, a través de múltiples vicisitudes, pero parece que se ha desembocado en un punto final, irrebasable en el que confluyen un conjunto de fuerzas que se precipitan a un grado extremo de exacerbación y efectos destructivos exponenciales sobre los mismos. Bajo un efecto de orden infinitesimal, se destruyen (en Irak y Siria) en cuestión de horas y minutos, bienes cuya construcción requirió de años y siglos de esfuerzos.

Ya de por sí, en la modernidad se fomentó un desprecio del el pasado, exhortando a su relegamiento y mirar hacia el porvenir. Lo que disminuye la importancia de la memoria, tanto como el interés puesto en el patrimonio cultural. Sin embargo el efecto de sensación de pérdida por la velocidad del cambio tecnológico, además de la desaparición y afectación de una gran parte de patrimonio en el mundo como consecuencia de una diversidad de factores y agentes, entre los que se cuenta principalmente la agresión bélica, motivaron a reavivar el interés por su preservación. El gran giro que Pierre Nora ubica en los años 70 y tiene su punto de culminación en el año de 1980 con el "año del patrimonio"2.

En efecto, ante el panorama de borramiento que cayó como un velo de amnesia después del periodo trágico en América Latina durante la segunda mitad del siglo XX, y la anulación de ese horizonte de esperanzas, se produjo una fiebre de reivindicativa de la memoria y la patrimonialización de la cultura. Lamentablemente, en el ámbito

2 NORA, Pierre. Pierrre Nora en Le lieux de memoire. Montevideo: TRILCE, 1992. p. 179-180. 
mundial se pasó al extremo opuesto mediante estrategias que señala Andreas Huyssen: "el exceso de memoria crea tal sobrecarga que el mismo sistema de memoria corre un constante peligro de implosión, lo que a su vez dispara el temor al olvido"3. En efecto Ello ha dado lugar a un cuestionamiento sobre la posibilidad de la memoria y su capacidad para rescatar y preservar el testimonio de lo acontecido.

Pero la memoria no depende ni consiste sólo en recuperar información, incluso no es característica suya la capacidad de reproducir con fidelidad literal el pasado. Desde la literatura y la filosofía se constata que: "la memoria ante todo, nos miente." Si la memoria es imperfecta, defectuosa, y no es tan fiel como puede serlo un registro fotográfico o cinematográfico del pasado, esa limitación está en su naturaleza. Incluso si se posee una muy buena memoria, ésta siempre estará hecha de parcialidades. El ejemplo de Funes el memorioso de Jorge Luis Borges, es una muestra literaria de lo que implicaría una capacidad de retención absoluta, exhaustiva, paralizante e imposible de procesar.

Quizá la definición más pertinente para la memoria, no sea la de una capacidad para capturar y reflejar con fidelidad el acontecer vivido, sino de metonimizar, resignificar y modelar lo que recupera de un pasado revisitado, con todo lo que los sujetos portan consigo de cuentas pendientes, culpas, anhelos no realizados y modos culturales de recordar.

La memoria es más bien una especie filtro con relación a lo que experimentamos y registran nuestros sentidos. Si tamiza culturalmente nuestra percepción de lo vivido, puede que opere mediante un código en el que intervienen funciones como la de identificación, reconocimiento, la metonimia y la asociatividad, ligadas a su vez a los mecanismos simbólicos del subconciente.

\section{LA MEMORIA, ¿SUJETA A LA HISTORICIDAD?}

¿Cómo puede ser todavía la memoria un referente de orientación para nuestra conciencia del tiempo, especialmente en las condiciones actuales de aceleración del presente y dilatación del pasado, así como de memoria sin historia ${ }^{4}$, y que aún así, se le considere como un componente esencial de la identidad y la hace posible?

\footnotetext{
${ }^{3}$ HUYSSEN, Andreas. En busca del futuro perdido: cultura y memoria en tiempos de globalización. México D.F.: Fondo de Cultura Económica, 2002. p. 23-24

${ }^{4}$ MONGIN, Olivier. Memorias in Historia. Punto de Vista, Buenos Aires, n. 49, 1994.
} 
Nuestra noción del mundo puede diferir considerablemente, según el momento de la Historia en el que nos encontremos. Así, nuestra relación con el presente y el futuro, vendría ser único e (históricamente) irrepetible en la modernidad. En ese caso, la memoria tampoco jugaría siempre el mismo papel y podría tener una función distinta en cada configuración histórica y social singularizada. Por ello cabe preguntarse sobre ¿qué puede suceder con la memoria en un tiempo que se experimenta como un presente perpetuo $?^{5}$

La relación con el tiempo parece haber cambiado sustancialmente al pasar de la modernidad a la postmodernidad o modernidad tardía. Así lo han hecho notar diversos autores ${ }^{6}$. Actualmente nos cuestionamos mucho sobre la relación con el pasado y lo que este representa ante la perspectiva de un futuro que se vuelve indiscernible como horizonte o se vislumbra de manera confusa como algo incierto.

Quizás ese es el sentido que señala Marc Augé cuando señala que: "la historia venidera ya no producirá ruinas. No tiene tiempo para hacerlo"...en que "los edificios no se construyen para envejecer" ${ }^{\prime 7}$ De 26 años a acá, no quedan restos del Muro de Berlin ¿Nos encontramos acaso ante algo como el "fin de los vestigios", aparte de otros agentes que perpetran la destrucción de vestigios como los de Palmira en Siria?

La memoria alude tanto a su función como un instrumento de recapitulación ${ }^{8} y$ recuperación (anamnesis) así como porque es la manera de producir un sentido al devenir histórico al hacer posible la distinción entre sus momentos sucesivos. Procede también en ocasiones, como una especie de hermenéutica que opera en el plano de la imaginación y el medio por el que se toma conciencia en el seno del tiempo. Mediante la memoria se despliega una capacidad de reflexión sobre el proceso que nos conduce al momento presente como condición de la conciencia.

\footnotetext{
${ }^{5}$ Véase por ejemplo: MAFFESOLI, Michel El instante eterno. Paidós. AUGE, Marc. El antropólogo ante la globalización.

${ }^{6}$ Por ejemplo David Harvey (la compresión espacio-temporal) o Boaventura de Souza Santos a propósito
de la visión crítica del tiempo proléptico. ${ }^{6}$ GONZÁLES-VARAS, Ibáñez Ignacio. Las ruinas de la memoria: ideas y conceptos para una (im) posible teoría del patrimonio cultural. México D.F.: Siglo XXI, 2014, p. 22.

${ }^{7}$ AUGÉ, Marc. El tiempo en ruinas. Barcelona: Gedisa, 2003. p. 1, 8 y 156.
} 
Se dice que

el presente del pasado ha alcanzado tal actualidad en los últimos decenios que se puede hablar de un efecto de inflación del mismo, y que la memoria ha cobrado un inédito protagonismo sobre la historia, siendo que esta constatación tendrá importantes consecuencias para el patrimonio, su definición y conservación (VARAS IBÁÑEZ, 2014, p. 22).

Aunque, una memoria saturada como dice Régine Robin ${ }^{9}$ bien podría ser una de las más evidentes formas de olvido.

El antropólogo Marc Augé plantea que "las conmemoraciones son el solapamiento de una memoria desaparecida "... "cuyo atractivo nace como en la dama de las Camelias, de la extenuación" 10 Esto nos hace pensar si ciertos sitios, consagrados como lugares de memoria podrían llegar a ser parte del fenómeno conmemorativo al que también ha hecho alusión Pierre Nora en que la versión conmemorativa de la memoria, es presa de una ambigüedad y la ironía consistente en el ocultamiento que dicho tipo de actos conlleva.

Uno de los acercamientos prometedores para acudir al pasado revisitado desde la memoria, es la de su apreciación por lo que contiene como promesa de futuro (a la que aludía Ernst Bloch ${ }^{11}$ y exigencia de realización de anhelos y proyectos muchas veces impedidos, pero han quedado en estado de latencia. La memoria ha hecho posible su conservación en ese estado promisorio como reserva de futuro.

\section{¿LA MEMORIA NOS MIENTE?}

En la memoria, se reconoce la facultad de retención y preservación de las experiencias sobre lo que acontece y tiende a desaparecer. Sin embargo, el esfuerzo de recordar, no nos remite al pasado tal y como este realmente ha acontecido o lo vivimos, sino que al recordarlo lo cambiamos. ¿Qué tanto transformamos lo acaecido al recordar, si este hecho es también -como materia del recuerdo- el de imaginar y un acto afectivo?. Al recordar, rescatamos parcialidades de nuestras vivencias; en segundo lugar,

\footnotetext{
9 ROBIN, Régine, La mémoire sataurée.

${ }^{10}$ AUGÉ, Marc. Hacia una antropología de los tiempos contemporáneos. Barcelona: Gedisa, 1995 Asimismo; El Tiempo en Ruinas. Barcelona: Gedise, 2003. p. 124.

${ }^{11} \mathrm{BLOCH}$, Ernst, El principio esperanza. La Trotta.
} 
regresamos al pasado inducidos por los imperativos y la visión del presente, y entonces la memoria viene a ser una suerte de interpretación selectiva y versión subjetiva acerca del pasado realmente acontecido, más que su registro fiel. Por ello es que el hecho de recordar es quizá un esfuerzo por conferir un sentido a lo pasado y no necesariamente su mera distorsión.

La memoria (individual) conduce a un darse cuenta y reconocer, como en un descubrimiento, aspectos reveladores de lo conocido que no había uno advertido. El pasado -así revisitado- es un lugar en donde uno encuentra cosas que aparecen bajo una nueva luz (lo nuevo en lo conocido) como si tuviesen un nuevo significado. El haber vivido, representa un primer recorrido, percibiendo las cosas todavía desde las sombras de la caverna, bajo el efecto de un deslumbramiento. No en balde la rememoración (segundo momento) deja en ocasiones un sentimiento de satisfacción; de que algo por fin se ha completado, y permite que se produzca algo equivalente al reconocimiento.

Como se sabe, ciertas rememoraciones pueden ser incisivas, reveladoras y dolorosas (como las que hace posible la terapia psicoanalítica), con ellas surge lo que se había reprimido.

Quizá la memoria hace posible recoger y rescatar los rastros simbólicos que dejan nuestros incontables actos vividos de manera más o menos apurada y mirando casi siempre hacia el futuro, porque se nos impone una perspectiva proléptica, mientras la memoria hace posible precisamente en contrapartida y a contracorriente, el recorrido a la inversa: la analepsia (el proceso que va del presente hacia el pasado) puesto que siempre se necesita más tiempo para recapitular y asimilar lo que vamos generando a nuestro paso. Nos toma tiempo recapitular frente al desbordamiento en el que nos atrapa el presente. La memoria nos hace volver por donde venimos. El pasado revisitado por medio suyo adquiere un sentido diferente.

La anamnesis no es sólo una recuperación cualquiera de la memoria como ahora se estila, sino que se remonta a la contemplación de las reminiscencias, que son las "ideas de antes del nacimiento, el pasado primigenio o lo ahistóricamente eterno" (BLOCH, p. 32). En el fondo de la memoria profunda, se halla lo arquetípico.

La memoria a su vez (como la conciencia) es también -y principalmente- una forma de repliegue del sentido temporal de lo vivido sobre sí mismo. Por eso para la filosofía socrática la memoria era un aspecto cognoscitivo fundamental. 
El sentido del paso del tiempo y su rememoración, se relaciona con experiencias subjetivas y estados anímicos evocativos como el spleen o la nostalgia, que no se perciben por lo general en términos del presente inmediato vivido, sino en virtud del contraste que suscita la añoranza y sentimiento de pérdida que produce el transitorio paisaje humano. Ese efecto de menoscabo, denota una forma de conciencia, incluso una perspectiva del mundo como puede ser la de la conciencia desdichada.

\section{MEMORIA Y OLVIDO}

El proceso de olvidar, -según Manfred Osten- acontece de modo creciente y de manera alarmante en la actualidad, constituye un fenómeno que debe ser tomado en cuenta seriamente ${ }^{12}$.

La memoria guarda una relación consustancial y constitutiva con el olvido, como la estructura ausente que subyace a lo recordado, o su prolongación omitida. Paul Connerton ha hecho mención de siete formas de olvido ${ }^{13}$. Hay por lo menos tres aspectos o tipos y funciones-efecto de olvido: uno es para la recuperación descriptiva, que hace posible por ejemplo el Performance (Phelan); otro es el que permite soportar las experiencias traumáticas (Freud); y otro... para perdonar (Julia Kristeva).

Desde Freud, el olvidar habría perdido su inocencia (como dice Manfred Ostrom) y sabemos que lo que se olvida, no ha desaparecido en realidad, sino que pasa a ocupar un lugar en el inconciente (individual y en el ámbito social). En ocasiones vuelve de forma enmascarada y se manifiesta por otros medios no menos eficaces que la propia memoria, como son los oníricos y los simbólicos. Podría decirse que lo que se olvida, es lo que ha pasado a formar parte de una reserva u otro registro de la memoria (denegada, reprimida u omitida) que los sujetos (individuales o colectivos) sintomáticamente no reconocen (denegación) como suya. El lugar del olvido parece liberado de toda culpa, como resultado de lo involuntario y lo no deliberado. La alusión al olvido da la impresión de un abandono, pero en el hecho de olvidar subyace pese a todo una forma de intencionalidad. Según Freud, el olvido es una forma de memoria oculta.

\footnotetext{
12 OSTEN, Manfred. La memoria robada: los sistemas digitales y la destrucción de la cultural del recuerdo: breve historia del olvido. Madrid: Siruela, 2008. p. 69, 75.

${ }^{13}$ CONNERTON, Paul. Seven types of forgetting. Memory Studies. 1-59-71. Se trata de las siguientes formas: borramiento represivo, olvido prescriptivo; olvidos constitutivos de una nueva identidad; amnesia estructural; olvidos como anulaciones; olvidos como algo obsoleto y planeado; y olvido como un silencio humillante.
} 
Lo que suele darse es más bien una forma deliberada de escamoteo u omisión muy precisa de ciertos recuerdos de actos o acontecimientos que pasan por residuales. La memoria arrastra consigo lo que la completaría y sin embargo no se atreve a reconocer. En su parcialidad y ocultamiento se asemeja a la de la ideología.

Ricardo Forster alude a lo que denomina como las astucias del olvido ${ }^{14}$ y se pregunta si ¿acaso no es necesario olvidar para recordar? El planteamiento hegeliano sobre la astucia de la razón, la cual se impone en la historia por los caminos más erráticos, así como a través de lo que se le opone, hace pensar en lo que podría ser una astucia de la memoria. Esto tendría que ver con el del retorno de lo reprimido. Lo que pretende olvidarse vuelve aunque sea por distintos medios, como lo visualizaba Walter Benjamin, "colándose por los intersticios del presente sin pedir permiso" (dice Forster).

Paul Ricoeur, sostiene -siguiendo a Agustín- que es la memoria la que retiene al olvido. Por eso el reconocimiento nos muestra que no hemos olvidado todavía totalmente lo que, al menos recordamos haber olvidado, puesto que lo recordamos y lo reconocemos. Es lo que recordamos haber olvidado. Hay entonces otro olvido que implica la privación de la memoria. Por eso para conjurar la amenaza de un olvido más radical, Agustín agrega al recuerdo de la memoria, el recuerdo del olvido ${ }^{15}$ (también retenido en virtud de la misma). El reconocimiento del objeto olvidado es lo que atestigua la existencia del olvido. Si es así, es la memoria la que retiene el olvido. Por otro lado, "¿cómo se puede hablar de la presencia del olvido mismo cuando olvidamos verdaderamente?...¿¿Qué he de decir si tengo la certidumbre de acordarme del olvido? ¿Habré de decir que lo que recuerdo no está en mi memoria? Lo que sé de cierto es que me acuerdo del olvido mismo, del olvido que sepulta nuestros recuerdos"16

Las astucias del olvido serían más deliberadas, para borrar la memoria del pasado no conveniente. Pero hay también formas de memoria que incurren -y en cierto modo producen una forma de- olvido, por ejemplo a fuerza de conmemorar algo, como efemérides; la mitificación, bien mediante la estetización (el revival como dice Forster)

\footnotetext{
14 FORSTER, Ricardo. Crítica y sospecha: los recursos de la cultura moderna. Barcelona: Paidós Ibérica, 2003. p. 53.

15 Gershom Sholem ha dado un ejemplo muy ilustrativo de economía de la memoria, cuando se refiere el caso de unos líderes espirituales que, para enfrentar una tarea difícil en beneficio de la Humanidad, tienen que realizar un ritual. Sin embargo a lo largo del tiempo, se van olvidando progresivamente de las condiciones que se requieren para llevarlo a cabo, al final de lo cual sólo les queda narrar la historia y logran a pesar de ello su objetivo. Gershom Sholem: las grandes tendencias de la mística judía. Siruela, 2012.

${ }^{16}$ RICOEUR, Paul. La memoria, la historia, el olvido. Buenos Aires: Fondo de Cultura Económica, 2000. p. 132.
} 
o banalizando el acontecimiento. Pero también desactualizándolo y descontinuándolo, convirtiéndolo en un anacronismo inservible. Es el caso del que se ocupa Ricardo Forster en su ensayo Los Usos de la Memoria (Forster, 2003). Aquí, el autor se propone dilucidar los motivos por los cuales de modo impresionante -más que en cualquier otro momento- las décadas de los 60's y los 70's, marcadas por las luchas revolucionarias en América Latina, quedaron descartadas de su relación con lo que constituye el presente. A sólo 20 o 30 años, toda vuelta a los testimonios de las luchas, deja un sabor de anacronismo y parece pertenecer a otro lenguaje y horizonte de sentido.

Lo que se advierte, es que algo sucedió como para que quedara desechado ese pasado. Todo indica que se llevó a cabo una especie de desmantelamiento y depuración de los fundamentos de la cosmovisión de toda una generación, así como una visión de la historia y la sociedad. Se le incomunicó y rompió el contacto con esa etapa y lo que fueron las convicciones apasionadas de esa generación. De ese modo se le impidió convertirse en objeto de memoria, esa memoria a la que alude Serge Moscovici, cuando señala que: lo proveniente del pasado sea más poderoso que lo proveniente del presente / de manera que/ En este dominio del mundo actual a través del mundo de ayer, reside la fuerza singular de las representaciones sociales ${ }^{17}$.

Podría decirse que el neoliberalismo, en la etapa siguiente de la postmodernidad, se ha organizado y desarrollado también como una política del olvido en el sentido más radical hasta ahora conocido. Colocándose en la postura de la desideologización. Así, se ha levantado una barrera entre dos mentalidades, una de las cuales se aferra a convicciones y certezas; modos de identificación y representación, así como formas de discurrir y argumentar que han quedado desacreditadas o que parecen inviables, precisamente para quienes serían sus herederos naturales, pero experimentan una desidentificación, ya que no surgen de su situación y no impelen a actuar.

\section{MEMORIA Y CULTURA}

Xerardo Pereiro ${ }^{18}$, sostiene que: "La memoria implica... un juego social entre recuerdo y olvido en el cual la cultura es un poderoso filtro. Lo que una persona recuerda de un hecho está influido por su visión del mundo, algo creado por su cultura". Entonces,

\footnotetext{
${ }^{17} \mathrm{MOSCOVICl}$, Serge; HEWSTONE, Miles. De la ciencia al sentido común. In: Psicología Social II: pensamiento y vida social: psicología social o problemas sociales. México D.F.: Paidós, 2008. p. 709.

${ }^{18}$ PEREIRO, Xerardo. Apuntes de antropología y memoria. Rev. O Fiadeiro - EI Filandar. n. 15.
} 
según esto, cultura y visión del mundo constituyen un registro que rige la selectividad sobre lo que se preserva deliberadamente y lo que se relega a otro tipo de depósito. El olvido total, quizá se da sólo con la muerte y la ruptura de la transmisión. Jan Assmann por su parte, propone un concepto de memoria cultural ${ }^{19}$ como algo que abarca "lo primigenio, lo excluido, lo descartado...lo no instrumentalizable, lo herético, lo subversivo, lo separado".

Si esto es así, habría que proceder a la identificación de los mecanismos culturales sobre aquello que las propias sociedades pueden llegar a descartar, y con ello tenemos una distinción más, que se agrega a las existentes entre cultura y patrimonio cultural, pues aunque la patrimonial es una disposición eminentemente selectiva, tiene (como señala Manfred Osten) una vocación prioritariamente "compensatoria y protectora de la continuidad" en los memorabilia del recuerdo colectivo" (OSTEN, 2008, p.69 y 75). Los sistemas de significación tienen ascendiente sobre la memoria y prelación con respecto de lo que se va a recordar, que será en función de un cierto significado.

\section{ACELERACIÓN EN LA MODERNIDAD Y CULTURA VIVA}

Con la aceleración de la experiencia en la modernidad, hay también una aceleración del olvido (como ha hecho notar Reinhart Koselleck). Y no se trata tanto de un olvido como de una forma de amnesia. Una función de la tradición, tan criticada en la modernidad, ha sido precisamente la de preservar la memoria y mantenerla actualizada y vigente mediante los hábitos sociales y mentales, aunque la conciencia de su razón se pierde a veces en el proceso de su mantenimiento. Este dispositivo tan organizado en el plano social, aparecía para la modernidad como atavismos que obstaculizaban los avances prometedores del progreso. Sin embargo, la modernidad no generó un recurso alternativo para la preservación de la memoria, antes bien, se esmeró en desarrollar lo que tendía a contrarrestarla con su fe compulsiva en el futuro y su horror anacrofóbico ${ }^{20}$ por el pasado como si fuese un tabú 21 .

\footnotetext{
${ }^{19}$ ASSMANN, Jan. ¿Qué es la memoria cultural? Rev. Pensamiento de los Confines. Fondo de Cultura Económica de Argentina, n. 21, dic. 2007. p. 212.

${ }^{20}$ Puede definirse como el sentimiento de horror por un pasado que se considera vetusto y decadente, cuyos restos y vestigios, ambientes y valores producen un efecto depresivo y thanatofóbico. Es el síntoma de una evasión y el intento de evitar -como un tabú- el contacto con ese pasado e incorporarse en la agitación amnésica y fugaz de la vida moderna.

${ }^{21}$ Acerca de la lectura de Fausto (y el pasaje de Filemón y Baucis) como odio al pasado Véase: OSTEN, Manfred: 2008. p. 26-31.
} 
Además está lo que señala Manfred Osten (2008) como una crisis de los medios de digitalización, ya que disponen de una memoria a corto plazo y han caducado los instrumentos para leer los escritos electrónicos de los años sesenta, lo que significa que nos estaríamos enfrentando a la pérdida de la mayor parte del material almacenado y no hay clara conciencia de las implicaciones culturales de este hecho.

Por ello no es despreciable que en ámbitos más tradicionales y con ocasión de la reivindicación del patrimonio cultural a nivel mundial por parte de la UNESCO, la cultura viva aparezca como alternativa ante la crisis de los sistemas de almacenamiento de la memoria. En ese contexto, la transmisión, más que la conservación física, adquiere una particular relevancia, en tanto que la memoria aparece como un aspecto -privilegiado por cierto- del propio patrimonio cultural inmaterial.

En efecto, resulta notable el hecho de que las expresiones performativas (que son dinámicas efímeras y evanescentes) adquieran una importancia especial como medios de transmisión. El papel del ritual, va en ese sentido, como un medio de preservación, no obstante que conlleva la desaparición, debido a su naturaleza efímera. Ello no quita que el ritual y la performatividad en general, constituyen medios idóneos para la preservación de la memoria, así como del patrimonio cultural intangible de las sociedades.

\section{MEMORIA INDIVIDUAL Y COLECTIVA}

La memoria colectiva era para M. Halbwachs, algo eminentemente social, a diferencia de Bergson, para quien era más bien individual. La idea de que lo social no sólo precede a lo individual, sino que es determinante y constitutiva, viene de Aristóteles, pero adquiere una vigencia paradigmática en los siglos XIX y XX, como episteme de la Sociología. Hoy, esa concepción de la manera como lo social incide en la conducta de los sujetos, se ha ido matizando y se visualiza a partir de diversas mediaciones, así como en una interacción con el albedrío y grado de iniciativa individual. No es la colectividad sino los sujetos quienes recuerdan, pero el recuerdo de las personas pasa por filtros culturales. Por otra parte, la identidad requiere de la memoria. Tanto la que pertenece a las vivencias subjetivas, como la del imaginario social ${ }^{22}$.

Para que el recuerdo que los otros nos traen pueda ser reconstruido sobre un base común según planteaba Maurice Halbwachs, nos dice Michael Pollack, tiene que

${ }^{22}$ En el terreno literario se debe a Sergio Pitol la famosa frase: "soy los libros que he leído". 
haber suficientes puntos de contacto entre nuestra memoria y las demás: “... es preciso... que ella no haya dejado de concordar con sus memorias y que haya suficientes puntos de contacto entre nuestra memoria y las demás para que el recuerdo que los otros nos traen pueda ser reconstruido sobre una base común"23 Además de selectividad, hay también un proceso de "negociación" para conciliar memoria colectiva y nuestras memorias individuales, nos dice Michael Pollack.

La memoria tal y como la concebían Durkheim y M. Halbwachs es una formación y una

fuerza casi institucional...en la duración, en la continuidad y en la estabilidad, que define lo que es un grupo y lo diferencia de los demás; fundamenta y refuerza los sentimientos de pertenencia y las fronteras socioculturales (POLLACK, 1989).

En efecto, estos representantes fundacionales de una nueva ciencia social, exponen leyes y principios, que dan cuenta de lo que es funcional de modo inherente a la sociedad, y por ello hacen énfasis en la función mnemónica de ciertos ritos y su papel cohesionador. Dan razón de lo que es positivamente lo social.

Sin embargo, al orientarse los estudios hacia lo que hay de diferente al interior de la sociedad y se pone atención a los excluidos y marginados, como dice Pollack, se advierte que hay una memoria subterránea, así como la existencia de una memoria oficial, además de que también en el terreno de la memoria se da una disputa y una lucha por la hegemonía. Podríamos decir también que se produce una diversidad de las memorias que denotan experiencias diferenciales $Y$ con ello, una redefinición de la memoria individual en ese nuevo contexto, reinscrita en una nueva relación con la memoria colectiva o social.

No todos recuerdan lo mismo, pero podemos imaginarnos la existencia de una memoria social disuelta entre los individuos que la comparten (especie de fondo revolvente) al que se recurre cada cierto tiempo. Para algunos autores incluso, no hay algo que materialmente distinga a una memoria colectiva, tratándose más bien de una especie de metamemoria (Henry Rousso, o J. Candau) o bien un patrimonio intangible de la sociedad. Relativamente homogénea, se estabiliza hasta cierto punto por la acción y el efecto de la comunicación, debido a lo cual refleja aspectos comunes, compartidos por muchos.

${ }^{23}$ POLLAK, Michael. Revista Estudios Históricos. Rio de Janeiro, v. 2, n. 3, 1989. p 3-15. 
Lo social se halla inscrito en lo más privado de la individualidad, como son los sueños. George Steiner ${ }^{24}$ ha constatado la recurrencia de sueños de brazos mutilados que tuvieron muchas personas durante el ascenso del nazismo en Alemania. Habría por tanto, una especie de memoria social de la que participan muchos en el plano más íntimo de lo onírico.

Nuestra certidumbre de la memoria es siempre personal, pero sabemos que es compartida, así como en comunicación con los otros. Esto produce cierta seguridad, pues vemos confirmada nuestra certidumbre acerca de lo que recordamos y que estamos en lo cierto, aún cuando las versiones propias puedan diferir de las de otros, como es frecuente.

\section{LO QUE NO SE PUEDE OLVIDAR}

Hay además, lo que no se puede olvidar (tal como lo describía vívida y elocuentemente Manuel Vázquez Luna, el joven guardián de la memoria ${ }^{25}$, víctima y sobreviviente de la masacre de Acteal en Chiapas, México). En los sucesos traumáticos, lo recordado resulta particularmente doloroso y puede producirse un bloqueo de la memoria, o por el contrario: de obsesiva y agobiante recurrencia. Quince años después (hasta su reciente fallecimiento) Manuel Vázquez Luna, confesaba con pesadumbre "no poder olvidar" al sobrellevar la memoria del asesinato brutal de su familia como una carga moral y por añadidura como una responsabilidad social ante la comunidad. Manuel prefería contar chistes a sus entrevistadores.

Aunque en la idea de que las experiencias traumáticas son intransferibles, autores como Primo Levi y E. Wiesel, tienen una visión escéptica. Para ellos los sobrevivientes no son los verdaderos testigos: "No somos los sobrevivientes los verdaderos testigos. Quien ha visto a la Gorgona no ha vuelto para contarlo, o ha vuelto mudo". Ese es el límite del relato del sobreviviente, su testimonio le es dado solo por delegación.

\footnotetext{
${ }^{24}$ Puede verse sobre los sueños compilados por Charlotte Beradt durante los años 30's en: GREENBLATT, Stephen. Sueños reales. En: SCHRÖDER, Gerhart; BREUNINGER Helga. Teoría de la cultura. Buenos Aires: Fondo de Cultura Económica, 2005.

25 Véase la entrevista en: http://martamoli.wordpress.com/2012/11/10/ahora-nos-toca-a-nosotros-serguardianes-de-la-memoria/.
} 
Wiesel sostiene incluso que: "Los que no han vivido esa experiencia nunca sabrán lo que fue; los que la han vivido no la contarán nunca; no verdaderamente, no hasta el fondo. El pasado pertenece a los muertos".... "como no hay nadie que haya vuelto para contar su muerte" (añade Levi) ${ }^{26}$. No parece haber memoria donde lo inenarrable prevalece.

Aunque el núcleo de la vivencia pueda ser incomunicable, el testimonio no deja de ser sin embargo un valioso recurso de alcance comunicativo. En contraste, la memoria social suele ser algo no experimentado por quienes la conservan.

Ahora veamos algunos ejemplos del modo como el proceso social incide en la representación de los hechos.

\section{EL IMAGINARIO SOCIAL COMO SUSTITUTO DE LA MEMORIA}

Un tema frecuente en relación con las resonancias ideológicas que resultan de acontecimientos históricos relevantes, es el referido a la tendencia a presentar las derrotas militares como si fuesen triunfos. Este es el caso por ejemplo de la batalla del 5 de mayo durante la invasión francesa en México y se conmemora cada año a nivel nacional y en Estados Unidos. Históricamente, a la victoria inicial del pueblo, le siguió una derrota aplastante, lo cual nunca se menciona o recuerda en las conmemoraciones cívicas.

Esta manera invertida o parcial de representarse el hecho histórico, es algo reiterado como fenómeno colectivo. La memoria colectiva se distingue claramente de la Historia (como ha señalado Pierre Nora). En ella interviene el imaginario social. Lo más significativo, es que nos encontramos en muchas ocasiones con una memoria de lo no acontecido (quizá una variante de invención de la memoria) ${ }^{27}$ Así, tenemos el caso del llamado "abrazo de Acatempan" que presuntamente se habría consumado para sellar la paz, entre Vicente Guerrero y Agustín de Iturbide, líderes de los grupos contendientes en la Guerra de Independencia de México. Este acto, nunca se llevó a efecto y sin embargo las comunidades de la región, llevan a cabo su representación cada año, para

\footnotetext{
${ }^{26}$ Citado por Forster, El imposible testimonio: Celan en Derrida, p. 220-221.

27 En la definición que nos dan Eric Hobsbawm y Terence Ranger sobre la invención de la tradición , conviene destacar la forma arbitraria y circunstancial que resulta de una suerte de voluntarismo social -en apariencia- en la forma como surgen esas "tradiciones". HOBSBAWM, Eric; RANGER. Terence. La invención de la tradición. "Tradición inventada”.
} 
conmemorar el hecho. De esa manera sancionan algo que correspondería a un imperativo ético: de algo que debió haberse dado

\section{TRAER EL PASADO AL PRESENTE}

En el marco de la Revolución Mexicana, hacia el año de 1911 del siglo XX, un grupo de las fuerzas revolucionarias entronizó a una mujer indígena como reina en la localidad de Jamiltepec, Oaxaca con lo que se parecía reestablecer la continuidad truncada de un reinado similar en la misma región, representado también por otra mujer y más de cinco siglos de separación. El líder Domingo Ortiz y la gente indígena de la región de Pinotepa recurrieron a un elemento de la memoria étnica en la idea de consolidar su emplazamiento, reestableciendo el imperio mixteca y designando para ello a una "reina": María Benita Mejía, una mujer de pocos recursos, quien no obstante imponía respeto, dado que supuestamente descendía de la nobleza mixteca (entre la cual la mujeres gobernantes no eran algo fuera de lo común ${ }^{28}$. La tentativa fue efímera, sin embargo puso al descubierto la existencia de una tendencia recóndita y persistente en la conciencia regional.

Podría verse esto como un caso de restablecimiento utópico milenarista en el marco de una revolución campesina moderna, instaurando una forma histórica muy anterior. Una disposición de larga duración que denota la aspiración de instaurar ciertas figuras de poder, y se halla latente en la memoria colectiva, lista para ser instaurada en cuanto se presente la ocasión.

Circula una versión compartida por algunos estudiosos aunque se le toma por una leyenda, según la cual esta región existió en tiempos prehispánicos un reinado femenino. Con varios siglos de diferencia, se produjo un intento de reestablecer otro similar en el contexto de una revolución social. Como si la memoria (o algo que juega el papel de la misma) hubiese emergido en la ocasión históricamente oportuna -no para recordar- sino más allá: para repetir el hecho y establecerlo en la realidad presente. Este podría ser un ejemplo de los casos en que la memoria social puede servir como el instrumento de una voluntad colectiva y dar realidad a las promesas del pasado.

\footnotetext{
${ }^{28}$ Retorno al Imperio Mixteco, 30 de septiembre de 2012. Disponible en: <http://pinodebate.blogspot. $\mathrm{mx} / 2012 / 09 /$ retorno-al-imperio-mixteco.html>.
} 
Quizá en los fenómenos mesiánicos y milenaristas, la función de la memoria sea más un imperativo de reaparición de algún personaje o un determinado orden en la propia realidad; ya sea la de traer -literalmente- un pasado hacia el presente, más semejante a la invocación ritual (como es el caso de la reina mixteca) que una rememoración, mentalmente evocada.

No es la memoria en sentido estricto, de lo experimentado y a lo que los testigos hubiesen asistido en vida. Impresiona más bien la distancia histórica que hay de por medio. Y con la idea de una memoria étnica ${ }^{29}$, se sugiere que podría haber algo así como una disposición transmitida de muy atrás: la de un modelo de autoridad y gobierno.

Sucede que lo que muchas veces se toma como memoria, es en realidad la retención de modelos, símbolos, principios estructurantes, por ejemplo en relatos. Asimilados y transmitidos por los sujetos en el seno de un determinado medio o grupo sociocultural. Se tiene así una especie de memoria de lo aprendido; de lo que "se dice o se sabe que ha sucedido" y se preserva de modo compartido. Y el hecho de no ser mediada por la experiencia directa, permite una cierta laxitud con respecto de la exigencia de comprobación acerca de su certeza.

Esta memoria puede ser un acopio de representaciones sociales o lo que procesa de modo imaginario una sociedad. No se basa en los referentes de tiempo y lugar. Es una memoria de lo que no puede confirmarse y puede confundirse con la ficción. En ese sentido, lo que aparece como memoria étnica vendría a ser la persistencia de las representaciones sociales imaginarias de un grupo cultural. Quizás a eso se refiera en parte, el concepto de memoria imaginada de Arjun Appadurai ${ }^{30}$

Actualmente, en el medio habitual, apenas se alude al tema y la referencia acerca de un reinado ancestral, es algo que se toma como una leyenda y sólo algunos estudiosos (como Gutierre Tibón) han hecho alusión al mismo.

\footnotetext{
29 Jacques Le Goff y Leroi Gourhan han aludido en distintos momentos a la memoria étnica.

30 APPADURAI, Arjun. La Modernidad Desbordada. Fondo de Cultura Económica.
} 


\section{EN CONCLUSIÓN}

Las representaciones sociales recubren los hechos históricos, con lo que, éstos no necesariamente se deforman, sino que llegan a adquirir en ocasiones una profundidad simbólica inusitada. Lo que una persona aprende durante el tiempo de vida llega a formar parte de la propia identidad y muchas veces resulta difícil distinguir la huella de lo experiencia de lo vivido, con respecto de la memoria de lo aprendido, especialmente si esto se ha dado en la infancia temprana. En efecto, ¿cuántas veces lo que se da como memoria, lo que no es sino la reproducción de un modelo, o un habitus discursivo y narrativo adquirido, que se acopla a situaciones vividas?. Quizá la sensación del dejá vu se debe a ese tipo de correspondencias.

La Historia, sigue recogiendo sus materiales de lo que le brinda la memoria colectiva y el patrimonio cultural se halla entre ambas, saliendo librado de sus discrepancias. Ante la crisis vertiginosa que se cierne actualmente sobre la Historia y la memoria, así como ante la destrucción indiscriminada, sin esperanza de recuperación y la saturación de "memoria" sin selección ni aprovechamiento, procede disponer de la memoria como algo que haga posible la reconstrucción del sentido, como un hilo que pudiésemos seguir, internándonos en el laberinto del tiempo y nos permita sortear los diferentes tipos de olvido.

\section{REFERENCIAS}

ASSMANN, Jan. ¿Qué es la Memoria Cultural? Rev. Pensamiento de los Confines. Buenos Aires, n. 21, dic. 2007.

AUGÉ, Marc. El Antropólogo ante la Globalización. México D.F.: Siglo XXI, 2014.

. El tiempo en ruinas. Barcelona: Gedisa, 2003.

. Hacia una antropología de los tiempos contemporáneos. Barcelona: Gedisa, 1995.

APPADURAI, Arjun. La modernidad desbordada. Buenos Aires: Ediciones Trilce; Fondo de Cultura Económica, 2001.

BLOCH, Ernst. El principio esperanza. Madrid: Trotta Editorial, 2006.

CONNERTON, Paul. Seven types of forgetting. Memory Sudies. Los Angeles, v.1, n.1, p. 59-71. 
DE SOUZA SANTOS, Boaventura. Una epistemología del sur: la reinvención del conocimiento y la emancipación social. Buenos Aires: Siglo XXI; CLACSO, 2009.

FORSTER, Ricardo. El imposible testimonio: Celan en Derrida. Cuadernos de Filosofía Latinoamericana. Vol. 33, no. 107, 2012 , p. 175-193. Disponível em file:///Users/francisca michelon/Desktop/645-1677-1-PB.pdf Crítica y sospecha. Barcelona: Paidós Ibérica, 2003.

GONZÁLES-VARAS, Ibáñez Ignacio. Las ruinas de la memoria: ideas y conceptos para una (im)posible teoría del patrimonio cultural. México D.F.: Siglo XXI, 2014.

GREENBLATT, Stephen. Sueños reales. In: SCHRÖDER, Gerhart; BREUNINGER, Helga. Teoría de la cultura. Buenos Aires: Fondo de Cultura Económica, 2005.

HARVEY, David. La condición de la postmodernidad: investigación sobre los orígenes del cambio cultural. Buenos Aires: Amorrortu, 1998.

HOBSBAWM, Eric; RANGER. Terence. La invención de la tradición. Barcelona: Editorial Crítica, 2002.

HUYSSEN, Andreas. En busca del futuro perdido: cultura y memoria en tiempos de globalización. México D.F.: Fondo de Cultura Económica, 2002.

LE GOFF, Jacques. El orden de la memoria: el tiempo como imaginario. Barcelona: Paidós, 1991. MAFFESOLI, Michel. El Instante Eterno. Buenos Aires: Paidós, 2001.

MONGIN, Olivier. Memoria sin historia. Punto de Vista, Buenos Aires, n. 49, 1994.

MOSCOVICI, Serge; HEWSTONE, Miles. De la ciencia al sentido común. En: Psicología social II: pensamiento y vida social: psicología social o problemas sociales. México D.F.: Paidós, 2008. NORA, Pierre. Lieux de memoire. Montevideo: TRILCE, 1992.

OSTEN, Manfred. La memoria robada: los sistemas digitales y la destrucción de la cultural del recuerdo: breve historia del olvido. Madrid: Siruela, 2008.

PEREIRO, Xerardo. Apuntes de antropología y memoria. O Fiadeiro - El Filandar n. 15, 2004 POLLAK, MICHEL. Memória, esquecimento e silêncio. Estudos Históricos, Rio de Janeiro, vol. 2, n. 3, 1989, p. 3-15. 
RETORNO al Imperio Mixteco, 30 de septiembre de 2012. Disponível em: <http://pinodebate. blogspot.mx/2012/09/retorno-al-imperio-mixteco.html>.

RICOEUR, Paul. La memoria, la historia, el olvido. Buenos Aires: Fondo de Cultura Económica, 2000.

ROBIN, Régine. La mémoire sataurée. Paris: Un ordre d'idées, 2003.

SHOLEM, Gershom. Las grandes tendenciass de la mística judía. Siruela, 2012. 